Int. J. Dev. Biol. 54: 93-104 (2010)

doi: $10.1387 / \mathrm{ijdb} .092849 \mathrm{my}$

\title{
Competition for ligands between FGFR1 and FGFR4 regulates Xenopus neural development
}

\author{
MASAHIRO YAMAGISHI*,1,2,a and HARUMASA OKAMOTO1,3,b \\ ${ }^{1}$ Neuroscience Research Institute, National Institute of Advanced Industrial Science and Technology (AIST) \\ Central 6, ${ }^{2}$ Organ Development Research Laboratory, National Institute of Advanced Industrial Science and \\ Technology (AIST) Central 4, Tsukuba and ${ }^{3}$ Institute for Biomolecular Science, Gakushuin University, \\ Tokyo, Japan
}

\begin{abstract}
Cell-surface-localized receptors and their extracellular ligands usually comprise distinct families and promote diversity of signal transduction regulation. The number of available ligand molecules is often the limiting factor for receptor activation during interpretation of the signal by the responding cell. Limited ligand availability in a particular area of tissue should lead to local competition between different members of a receptor family for binding and subsequent activation. Fibroblast growth factor receptor (FGFR) 4 (FGFR4) is a less potent activator of downstream pathways than FGFR1, the major subtype of FGFR. Regional expression of Xenopus FGFR1 and FGFR4 (XFGFR1 and XFGFR4, respectively) overlap in the anterior part of prospective and developing neural tissue. In this paper we show that XFGFR1 and XFGFR4 have opposing effects on the positioning of expression domains of mid- and hindbrain markers when the expression levels of the receptors are altered. We present a line of evidence to support our hypothesis that competition between XFGFR1 and XFGFR4 for ligands is required for correct positioning of marker expression. Local competition between receptors with different potencies should provide an efficient means for a cell to interpret the ligand signal correctly, and may constitute a more general mechanism for regulating signal transduction.
\end{abstract}

KEY WORDS: FGF, receptor competition, signal transduction, neural development, Xenopus

\section{Introduction}

The binding of exracellular ligands to cell-surface-localized receptors initiates intracellular signaling in the target cell, which triggers cellular activities such as cell division, cell differentiation and cell movements. The diversity of receptor and ligand families enables the formation of various ligand-receptor combinations. Clarifying the mechanisms involved in cooperation among these factors is essential to understanding developmental regulation in vivo and for clinical applications.

Fibroblast growth factors (FGFs) and their receptors (FGFRs) constitute one of the major signal reception systems important for embryonic development and adult homeostasis. Four distinct FGFR genes (FGFR1 to FGFR4) are present in vertebrates and encode four receptor protein subtypes (Dailey et al., 2005; Eswarakumar and Schlessinger, 2005). The four FGFR genes are expressed in a range of embryonic and adult tissues in distinct but often partly overlapping patterns (Thisse et al., 1995; Hughes 1997; Hongo et al. 1999; Golub et al. 2000; Yaylaoglu et al., 2005; Lunn et al., 2007). Each FGFR subtype comprises an FGFbinding extracellular domain (ECD), a catalytic intracellular domain (ICD), and a short transmembrane domain spanning them. Ligand binding causes FGFRs to dimerize via the ECD, and the dimerization is followed by phosphorylation of the ICD kinase domain and downstream signaling. The Ras pathway, the phosphatidylinositol-3 kinase (PI3K) pathway and the phospholipase $\mathrm{C} \gamma(\mathrm{PLC} \gamma)$ pathway are the major signaling cascades downstream of FGFR activation.

Abbreviations used in this paper: FGFR, fibroblast growth factor receptor; ICD, intracellular domain; PLC, phospholipase C.

\footnotetext{
*Address correspondence to: Dr. Masahiro Yamagishi. Organ Development Research Laboratory, National Institute of Advanced Industrial Science and Technology (AIST) Central 4, 1-1-1 Higashi, Tsukuba 305-8562, Japan. e-mail: yamagishi-m@aist.go.jp
}

Present addresses: ${ }^{a}$ Organ Development Research Laboratory, National Institute of Advanced Industrial Science and Technology (AIST) Central 4, 1-1-1 Higashi, Tsukuba 305-8562, Japan. 'bInstitute for Biomolecular Science, Gakushuin University, Tokyo 171-8588, Japan.

ISSN: Online 1696-3547, Print 0214-6282 
The signaling properties of different FGFR/FGF combinations have been compared biochemically in several studies that used cultured cells (Vainikka et al., 1994; Wang, J.-K. et al., 1994; Shauol et al., 1995; Ornitz et al., 1996; Raffioni et al., 1999). Since those studies showed that all FGFR subtypes have similar intracellular signaling properties, the major difference in functions of the receptor ICDs may be quantitative rather than qualitative and reflect the varying strengths of kinase activity required to activate al., 2005). FGFR1 exhibits the strongest kinase activity and FGFR4 exhibits the weakest. Although possible qualitative differences in intracellular signaling events downstream of different FGFRs cannot be excluded based on current evidence, it seems likely that the diverse biological responses elicited by FGF binding arise largely from the different cellular contexts (Dailey et al., 2005).

The present study examined the functional roles of Xenopus FGFR1 and FGFR4 (XFGFR1 and XFGFR4, respectively) in early neural development. We found that the correct positioning of regional neural marker expression in Xenopus depends on the expression levels of XFGFR1 and XFGFR4. We then show that local competition between XFGFR1 and XFGFR4 for ligand underlying this regulation. Such receptor competition may enable a cell to efficiently interpret the ligand signal.

\section{Results}

\section{Differential expression of XFGFR1 and XFGFR4 is important for correct early neural development}

In the gastrula stage, strong XFGFR4 expression is restricted to the anterior region, whereas XFGFR1 is expressed broadly (Riou etal., 1996; Hongo etal., 1999; Golub etal., 2000). RT-PCR analysis showed that differential expression in the dorsal region became apparent by stage 10 (Fig. 1A) and persisted throughout gastrulation (not shown). Examination of a bisected embryo showed XFGFR1 mRNA distributed over the ectoderm and mesoderm in the outer tissue (including the leading edge of the involuting mesoderm; Fig. 1,D left), whereas XFGFR4mRNA was abundant within and anterior to the prospective midbrain-hindbrain boundary (MHB), which was marked by expression of the early MHB marker, XHR1 (Shinga et al., 2001) (Fig. 1D right,E).

To assess the significance of the XFGFR1 and XFGFR4 expression levels for early Xenopus development, we unilaterally common downstream pathways (Raffioni et al., 1999; Dailey et binding provides a consistent explanation for the mechanism

injected the prospective anterior neural region of embryos with the respective mRNAs (for overexpression) or morpholino antisense oligonucleotides (MOs) (for underexpression). Up- or down-regulation of FGF signaling in the marginal zone of early embryos impairs gastrulation by causing abnormal mesoderm development (Amaya et al., 1991; Thompson and Slack, 1992; Kroll and Amaya, 1996) and affects the shaping of neural structures during subsequent development. To prevent such defects, care was taken to accurately target the injections (Fig. 2A). After in situ hybridization for the MHB marker Xpax2 (Heller and Brandli, 1997), embryos that did not express $n L a c Z$ (a co-injected linear tracer) in areas anterior to the Xpax2-expressing region were excluded from the analysis.

Injection of XFGFR1 mRNA caused an anterior shift in Xpax2 expression on the injected side (Fig. 2B left,L line 2). In some injected embryos, only the lateral edge of the Xpax2-expressing region was directed anteriorly ("smiling phenotype"), most likely due to lateral distribution of the injected $\mathrm{mRNA}$ (Fig. 2B right, L line 2). By contrast, XFGFR4mRNA caused a posterior shift in Xpax2 expression (Fig. 2 C,L line 3).

Injection of XFGFR1-MO shifted Xpax2 expression posteriorly, whereas XFGFR4-MO induced an anterior shift (Fig. 2 $\mathrm{D}, \mathrm{E}, \mathrm{J}, \mathrm{L}$ lines 5 and 6 ). The phenotypes were mitigated or even reversed by coinjection with the rescue XFGFRmRNAs (Materials and Methods) with which antisense nucleotides do not hybridize (Fig. 2 F,G,L lines 7 and 8). The same pattern shifts were observed in expression of the other MHB marker En2 and the hindbrain rhombomere 3 and 5 marker Krox20 by altering the $X F G F R$ expression levels (data not shown). Thus, $X F G F R 1$ and $X F G F R 4$ showed opposing effects on marker expression when their expression levels were altered, demonstrating that the levels of expression of XFGFR1 and XFGFR4 are crucial for normal development of the neural region.

A

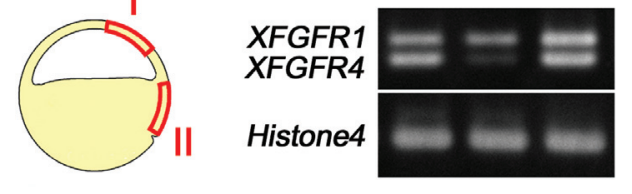

C

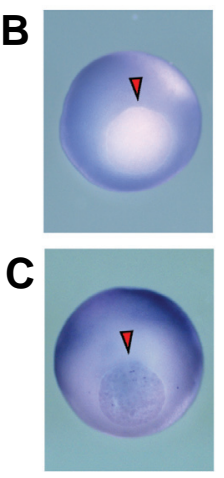
side of embryos. (A) RT-PCR analysis of XFGFR1 and XFGFR4 mRNAs in the prospective anterior region (I) and posterior region (II) (each 0.45 $\mathrm{mm}$ wide and $0.2 \mathrm{~mm}$ long) excised from the dorsal side of stage-10 embryos. W: whole embryos. (B,C) XFGFR1 (B) and XFGFR4 (C) expression in stage-11 embryos. Arrowheads indicate the dorsal blastopore groove. (D) A stage-11 embryo was sagitally bisected through the dorsal blastopore groove (arrowheads), and the halves were hybridized for XFGFR1 (left) or XFGFR4 (right). Dotted lines indicate the ectoderm/ mesoendoderm boundary. (E) A stage-11 embryo was sagitally bisected, and the halves were hybridized for XFGFR4 (left) or XHR1 (right). Before bisection, the dorsal side was flattened by gentle pressure to compare the distances between the posterior limits of the expression regions and the blastopore groove (arrowheads).

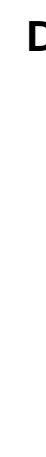

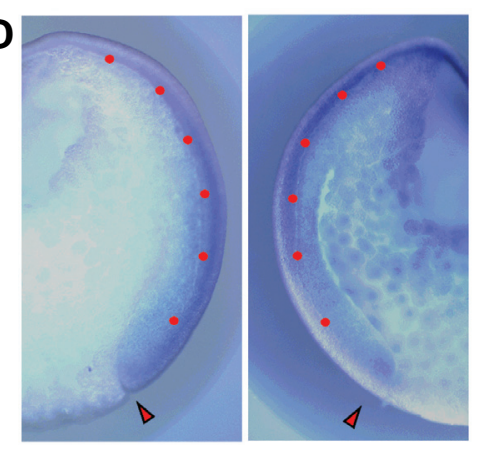

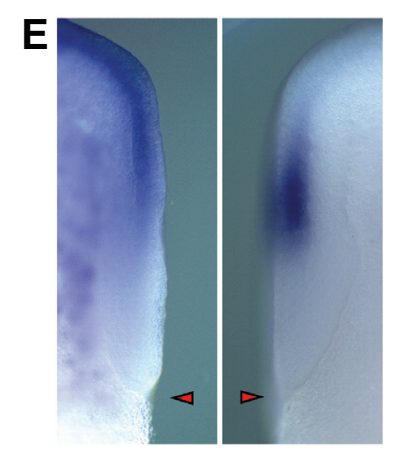


A
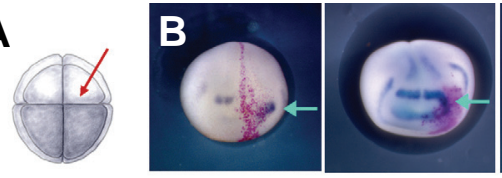

XFGFR1

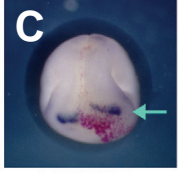

XFGFR4

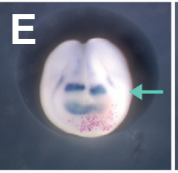

XFGFR4MO

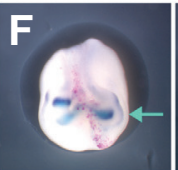

XFGFR1-MO

+ resXFGFR1

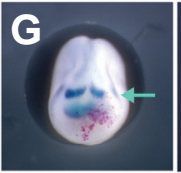

XFGFR4MO

+ resXFGFR4

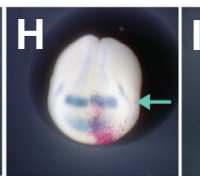

XFGFR1/4

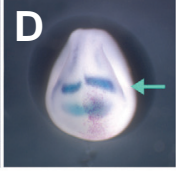

XFGFR1-MO

K

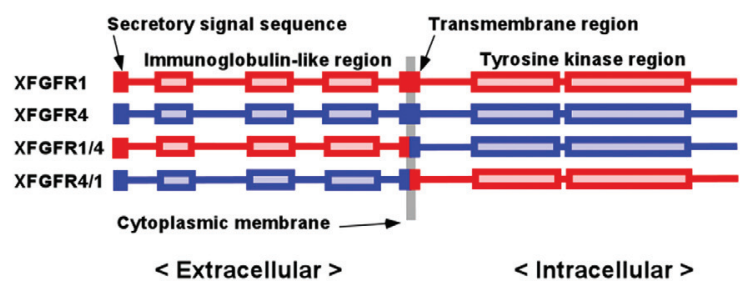

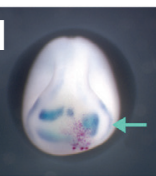

XFGFR4/1

< Extracellular >

$<$ Intracellular >

$\mathbf{L}$

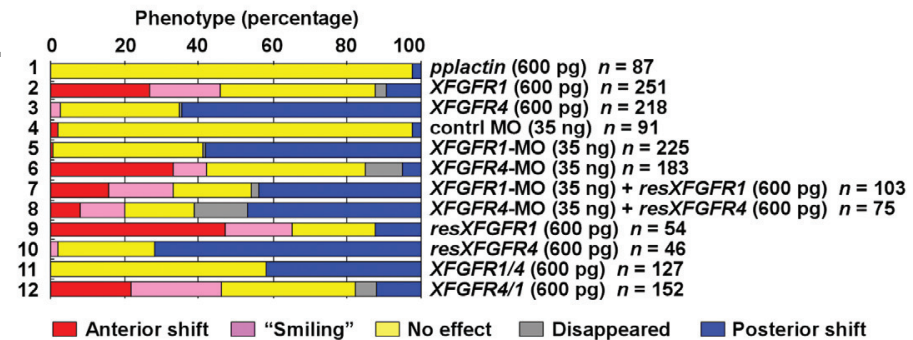

Fig. 2. Expression levels of XFGFR1 and XFGFR4 are important for normal development of the anterior neural region. (A) The site of microinjection at the 8-cell stage (animal view with dorsal side up) is indicated by the red arrow. (B-I) The embryos were examined for Xpax2 expression (blue) and $\beta$-galactosidase activity (red on the injected side). Green arrows indicate Xpax2 expression on the injected side. Xpax2 expression is shifted anteriorly by XFGFR1 mRNA (B left) andXFGFR4-MO (E), and posteriorly by XFGFR4 mRNA (C) and XFGFR1-MO (D). Some of the XFGFR1 mRNAinjected embryos exhibited a "smiling phenotype" (B right). The phenotypes induced by MOs were reversed by the rescue constructs, resXFGFR1 mRNA (F) and resXFGFR4 mRNA (G). The directions of the shifts are determined by the ICDs, as shown by injecting XFGFR1/4 (H) and XFGFR4/1 (I) mRNAs. (J) MO-mediated translational inhibition. UTRXFGFR1-GFP and UTRXFGFR4-GFP are the $5^{\prime}$ untranslated regions of XFGFR1 (plus the first 4 codons) and XFGFR4 (plus the first 8 codons) fused to GFP, respectively. Whole lysates from stage-11 embryos injected with mRNA (500 pg) and MO (35 ng) were analyzed by western blotting for GFP. myc-GFP mRNA was injected as an injection control. (K) Structures of the wild-type and chimeric XFGFRs. The regions of XFGFR1 and XFGFR4 are shown in red and blue, respectively. (L) Summary of injections. Preprolactin (pplactin) mRNA was injected as a control RNA.

\section{The extracellular domains of XFGFR1 and XFGFR4 are inter- changeable with respect to effect on marker expression patterns}

To determine whether the difference in the affinities of XFGFRs for FGF ligands contributes to their opposing effects on marker expression, we constructed two chimeric FGFRs: XFGFR1/4 composed of the ECD of XFGFR1 (XFGFR1-ECD) and the ICD of XFGFR4 (XFGFR4-ICD), and XFGFR4/1 with the opposite domain combination (Fig. $2 \mathrm{~K}$ ). Injection of these chimera mRNAs clearly showed that the ECDs of XFGFR1 and XFGFR4 are interchangeable: XFGFR1/4 shifted Xpax2 expression posteriorly and XFGFR4/1 shifted it anteriorly (Fig. $2 \mathrm{H}, \mathrm{I}, \mathrm{L}$ lines 11 and 12). This finding was somewhat unexpected in light of the different affinities of FGFs for different FGFRs. The strong link between the subtypes of the ICDs and the direction of the shift induced indicated that the total signal inputs at the ECDs of these two receptors are comparable in this region of the embryo and that the difference in signal outputs from the ICDs drives the marker shifting.

\section{XFGFR1 and XFGFR4 competition for ligands acts as the regulatory mechanism}

What is the mechanism underlying the opposing effects of XFGFR1 and XFGFR4 in directing Xpax2expression? We separated the process of receptor activation from that of ligand reception by using constitutively active (ca) forms of XFGFR1 and
XFGFR4 (caXFGFR1 and caXFGFR4, respectively; Materials and Methods; Fig. 3A, 4N). If the opposing effects simply arose from qualitative difference in the properties of the intracellular pathways downstream of XFGFR1 and XFGFR4, caXFGFR1 and caXFGFR4 should also show the opposing effects. However, both caXFGFRs shifted Xpax2 expression anteriorly, with caXFGFR4 only conferring the phenotype at a higher dose (Fig. $4 \mathrm{~A}, \mathrm{~B}, \mathrm{O}$ lines 1 and 2). Varying the dose of caXFGFR4 mRNA changed the frequency of marker shifting but not the direction of the shift (not shown). The results with the ligand-independent activated ICDs demonstrated that the intrinsic activities of the XFGFR1-ICD and XFGFR4-ICD are qualitatively indistinguishable with respect to effects on the direction of the shift in Xpax2 expression (i.e., shifting it anteriorly). The weaker shifting activity of XFGFR4-ICD is consistent with the notion that FGFR4-ICD is less potent than FGFR1-ICD as an activator of downstream pathways (Raffioni et al., 1999; Dailey et al., 2005).

The absence of opposing signaling effects by the caXFGFRs excluded the possibility that intracellular signaling events downstream of FGFRs determine the specificity of the direction of shifting. The requirement for intact ECDs in order for the opposing effects to occur revealed that the process of ligand reception is involved in regulation of the wild-type receptors. If the two XFGFRs compete for limited amounts of common ligands, an imbalance in the amounts of the receptors should alter the positioning of marker expression in opposing ways: anterior shifting of marker 
A

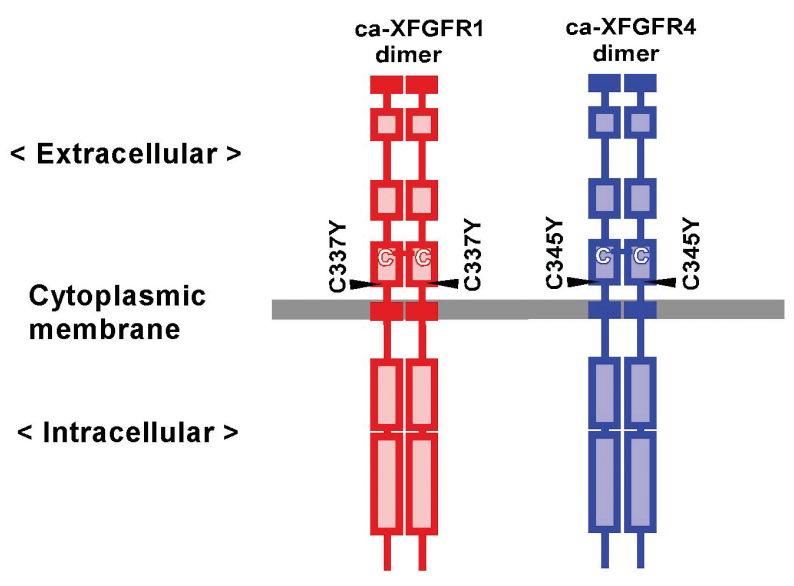

Fig. 3. Ligand-independent activation of the caXFGFRs (A) and iXFGFRs (B). (A) The C337Y and C345Y amino acid substitutions confer constitutive activity on XFGFR1 and XFGFR4, respectively, by forming intermolecular disulfide bonds between the monomeric receptors. As a

result of alterations to their immunoglobulin-like regions, the mutant receptors lose affinity for FGF ligands (Neilson and Friesel, 1995) and thereby lose their ability to compete with endogenous receptors for activation. (B) The ICDs of XFGFR1 and XFGFR4 were inserted between the myristoylation signal sequence and the AP20187-binding region, 2x FKBP36V-HA (yellow). Receptor dimerization/activation commences with the addition of AP20187. The structures of iXFGFR1 and iXFGFR4 are based on the mouse version of AP20187-inducible FGFR1 (Welm et al., 2002; Pownall et al., 2003).

expression should be caused by higher-than-normal signaling levels (generated by XFGFR1 overexpression or XFGFR4-MO injection) and posterior shifting should be caused by lower-thannormal levels (generated by XFGFR4 overexpression or XFGFR1$\mathrm{MO}$ injection). On the other hand, when ligand-independent signaling is generated, the signaling level should simply add to the endogenous level of FGF signaling, leading to anterior shifting irrespective of the ICD subtype. The results with caXFGFRs, whose ECDs are deficient with respect to FGF binding (Neilson and Friesel, 1995), were highly consistent with this proposed receptor competition mechanism.

To verify that FGF-independent activated receptors shift $X$ pax 2 expression anteriorly irrespective of the ICD subtype, we generated an additional set of altered XFGFRs by using the synthetic agent AP20187 (ARIAD) to induce FGFR dimerization/activation (Welm et al., 2002; Pownall et al., 2003). The ICDs of XFGFR1 and XFGFR4 were inserted between the myristoylation signal sequence and the AP20187-binding region $\mathrm{FKBP}_{36 \mathrm{~V}}$ to generate iXFGFR1 and iXFGFR4, respectively (Fig. 3B, 4N). Both iXFGFRs shifted marker expression anteriorly in the presence of AP20187, although the efficiency of iXFGFR4 was very low (Fig. 4 E,F,O lanes 5 and 6 ).

Different activating potencies of XFGFR1-ICD and XFGFR4ICD to activate ERK though the Ras pathway were confirmed in animal cap assays, which showed more robust activation by XFGFR1-ICD (Fig. 4K lanes 1 and 2, L lanes 8 and 9). Note that the difference in ERK activation between caXFGFR1 and caXFGFR4 reflected the intrinsic properties of the ICDs rather than differences in the dimerization efficiency of the ECDs, since interchanging the ECDs of these receptors did not significantly affect ERK activation (caXFGFR1 vs. caXFGFR4/1; caXFGFR4 stream pathways than XFGFR1-ICD. A similar difference in the levels of Xbra expression was observed when the wild-type XFGFR1 and XFGFR4 were overexpressed in animal caps (not shown), indicating that the signaling property inherent to each of the ICDs of the wild-type receptors were maintained in ligandindependent receptor activation.

To determine whether any receptor activation factors other than those related to ligand availability (for example, potential cofactors for receptor dimerization) are limited, we overexpressed FGFs. A small amount of eFGF mRNA (Isaacs et al., 1992) or FGF8a mRNA (Christen and Slack, 1997; Fletcher et al., 2006) resulted in the 'smiling' phenotype (Fig. 4 G,H,O line 7 and 8 ) and a low incidence of the anterior shift phenotype that was clearly restricted to the side of the embryos injected, but 'smiling' Xpax2 expression was frequent on both sides of the embryos (Fig. $4 \mathrm{H}$ ). This size reduction of anterior neural structures observed on both injected and non-injected sides of embryos was thought to reflect the diffusive nature of FGFs (Christen and Slack, 1999; Fletcher et al., 2006). Thus, our result with FGFoverexpression is consistent with receptor competition for ligands, since if ligand availability alone is limited, an increase in the FGF level would cause such size reduction of the anterior structures if the FGF were able to bind to and activate at least one of the four receptor subtypes. When XFGFR4 mRNA was co-injected, the anterior reduction caused by FGFoverexpression did not occur, and Xpax2expression on the injected side was shifted posteriorly (Fig. 4 I,J,O lines 9 and 10), indicating the importance of the balance between ligands and receptors in the positioning of marker expression. In this way, we confirmed that the positioning of marker expression is regulated by competition between XFGFR1 and XFGFR4 for ligands. 
The shift in Xpax2 expression in response to altering Ras and $P L C$ yactivation levels is consistent with the proposed receptor competition mechanism

If the positioning of marker expression was regulated by FGFR competition, the marker shift should also be observed when the activation levels of the intracellular pathways are altered. To look first at the Ras pathways, a constitutive mutation was introduced to XNrasto generate the oncogenic caXNras. Injection of caXNras mRNA shifted the Xpax2-expression region anteriorly (Fig. 40 line 11), the same as injection of caXKi-rasmRNA (not shown). In contrast, a dominant-negative ( $\mathrm{dn}$ ) form of ras, dnRas (Deng and Karin, 1994), induced a posterior shift in Xpax2-expression (Fig. 40 line 12). Thus, regulation of the Ras pathway is involved in the positioning of marker expression, and the direction of marker shifts is consistent with receptor competition as the mechanism that regulates the intensity of intracellular signaling.

The PLC $\gamma$ pathway is also activated by FGFRs, although its activation by FGFR4 is weak (Vainikka et al., 1994). To downregulate this pathway, we constructed mutant XFGFRs containing a tyrosine-to-phenylalanine substitution in the consensus YLDL sequence near the C-terminus, which abolishes direct activation of PLC $\gamma$ by the wild-type receptor (Mohammadi et al., 1992; Vainikka et al., 1994). The resulting XFGFR1 mutant form, XFGFR1 $1_{\text {Y762F }}$, was still capable of shifting the position of Xpax2 expression anteriorly (Fig. 40 line 13), but with significantly less efficiency (compare with Fig. 2L line 2). A comparable substitution in XFGFR4 (XFGFR4Y ${ }_{766 F}$ ) enhanced the ability of XFGFR4 to shift marker expression posteriorly (Fig. 40 line 14; compare to Fig. $2 \mathrm{~L}$ line 3 ). The difference in the intrinsic abilities of

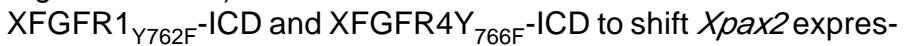
sion anteriorly were evident when the mutant ICDs were activated in a AP20187-dependent manner (Fig. 40 lines 17 and 18). Together, these results indicated that activation of the PLC $\gamma$ pathway by XFGFs is also involved in the positioning of marker expression. We then investigated whether PLC $\gamma$ itself is required for correct positioning of marker expression. An MO against

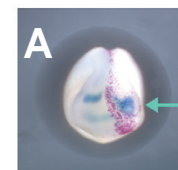

caXFGFR1

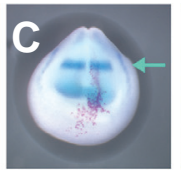

iXFGFR1

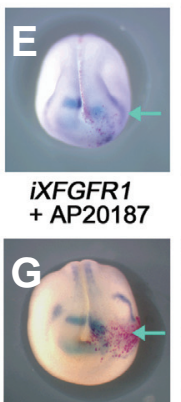

eFGF

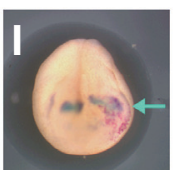

eFGF

+ XFGFR4

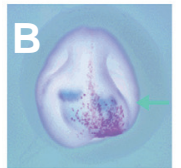

caXFGFR4

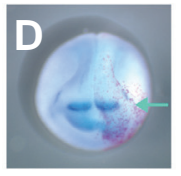

iXFGFR4

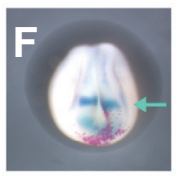

iXFGFR4
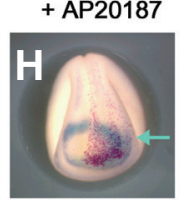

FGF8a

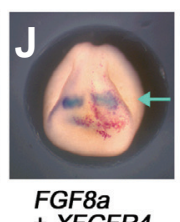

+ XFGFR4
XFGa

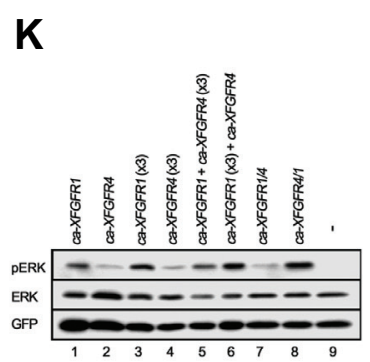

$\mathbf{L}$

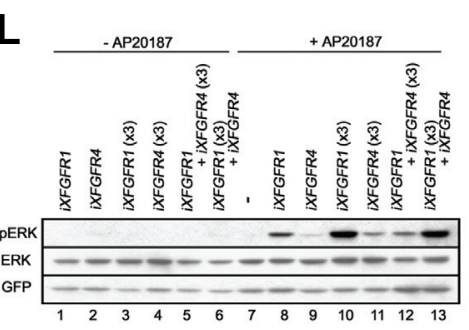

M

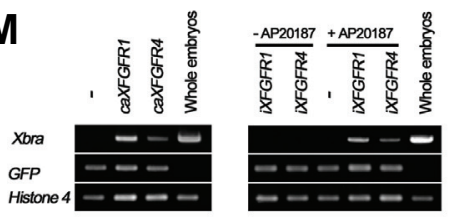

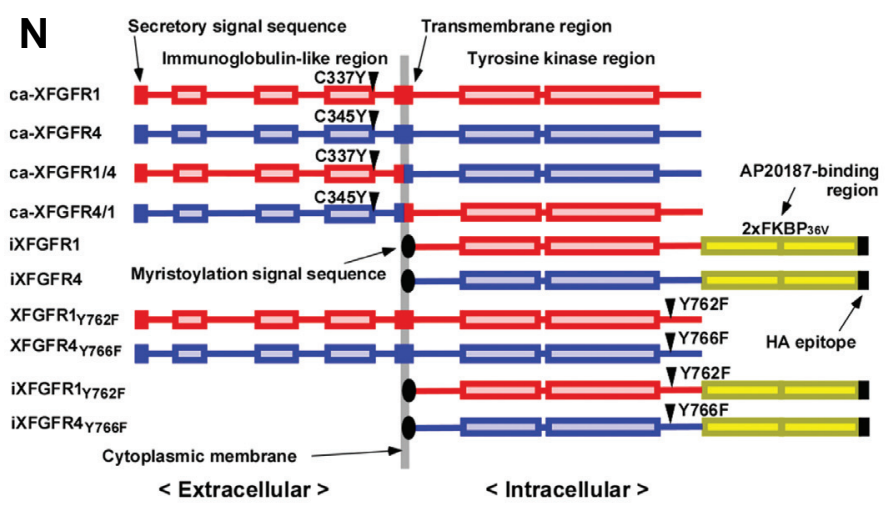

0

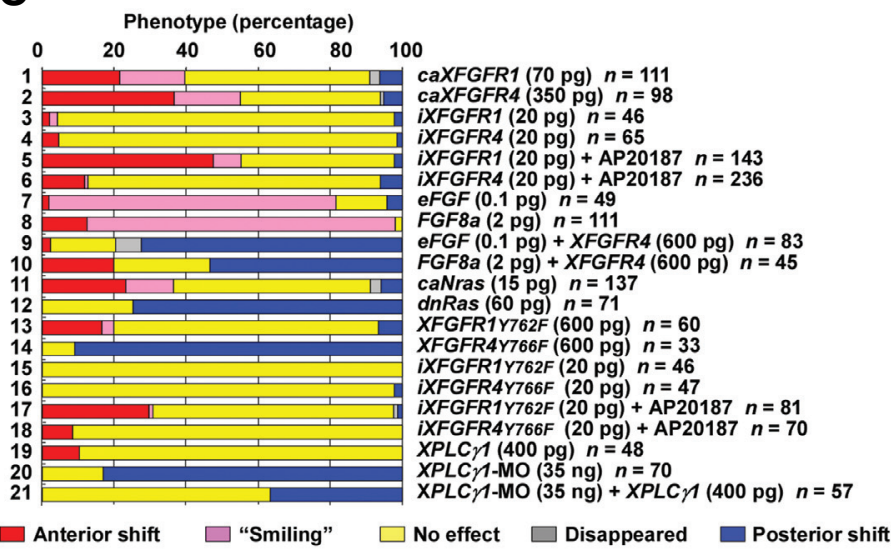

Fig. 4. Competition for ligands between XFGFR1 and XFGFR4 regulates the development of the anterior neural region. (A,B) caXFGFR1 $m R N A$ andXFGFR4 mRNA shifted Xpax2 expression anteriorly. (C-F) iXFGFR mRNA shifted Xpax2 expression anteriorly when AP20187 was added at stage 10 to dimerize the iXFGFRs. (G-J) WhenXFGFR4 mRNA was coinjected, the effect ofFGF overexpression (reduced size of the anterior neural structure in a cell-autonomous manner; $G, H)$ disappeared, and Xpax2 expression was shifted posteriorly (I,J). (K,L) ERK assay in animal caps injected with mRNAs encoding caXFGFRs and iXFGFRs. caXFGFR mRNA- and GFP mRNA-injected caps excised from blastulae were incubated at $230 \mathrm{C}$ for 110 min (K). AP20187 was added to iXFGFR mRNA- and GFP mRNA-injected caps at stage 10, and the caps were incubated at $230 \mathrm{C}$ for an additional 110 min (L). Cell lysates were analyzed by western blotting for phosphorylated ERK (pERK), pan-ERK, and GFP. (M) Induction of Xbra expression in animal caps injected with mRNAs encoding caXFGFRs and iXFGFRs. AP20187 was added at stage 9 for dimerization of iXFGFRs. RNA for RT-PCR analysis was extracted at stage 11. (N) Structures of caXFGFRs, iXFGFRs and their derivatives. (0) Summary of injections. 


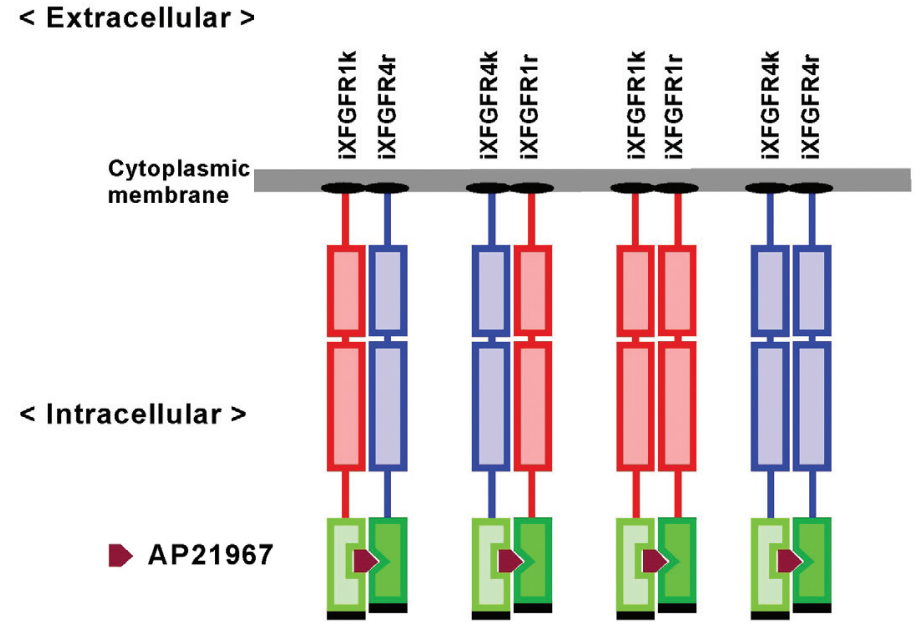

Fig. 5. Inducible heterodimerization of the XFGFR-ICDs. Since $A P 21967$ forms a bridge between FKBP (light green) and FRB2098L (dark green), heterodimers or homodimers of the XFGFR-ICDs can be selectively formed by the addition of AP21967 to embryos (or animal caps) injected with an appropriate combination of mRNAs.

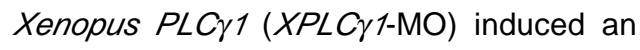
efficient posterior shift in Xpax2-expression (Fig. 40 line 20), and its effect was rescued by injection of XPLCY1 mRNA (Fig. 40 line 21).

The above findings show that the Ras pathway and the PLC $\gamma$ pathway contribute to the positioning of marker expression. The effects of altering the activation levels of these pathways were consistent with what was expected as a consequence of our receptor competition hypothesis.

The findings on the PLC $\gamma$ pathway also revealed that the degree of the relative contribution of the activation of this pathway by the wild-type XFGFRs to the positioning of marker expression was faithfully maintained when the ICDs were activated ligand-independently [(Fig. $2 \mathrm{~L}$ lines 2 and 3 ) vs (Fig. $4 \mathrm{O}$ lines 13 and 14); (Fig. 40 lines 5 and 6) vs (lines 17 and 18)]. Together with results on ERK activation (through the Ras pathway; Fig. $4 \mathrm{~K}, \mathrm{~L}$ ) and $X$ bra expression (through the Ras and PI3K pathways; Fig. 4M), the findings validate the

Fig. 6. Heterodimers between the intracellular domains of XFGFR1 and XFGFR4 activate for signaling. (A) Constructs for inducible heterodimerization. (B-D) Heterodimers between XFGFR1-ICD and XFGFR4-ICD as well as homodimers of XFGFR1-ICD shifted Xpax2 expression anteriorly. (E) The positioning of Xpax2 expression was unaffected by AP21967-induced homodimerized XFGFR4-ICD. (F) ERK assay in animal caps injected with different combinations of XFGFR-ICD mRNAs. Dimerization was induced by AP21967 at stage 10. (G) Summary of injections.

A

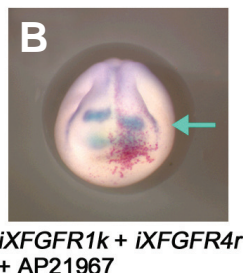
+ AP21967 use of ligand-independent receptor activation systems in investigating the outputs of the ICDs, and underscore the similarity in signaling processes downstream of XFGFR1 and XFGFR4.

\section{Heterodimers between XFGFR1 and XFGFR4 are active in terms of signal transduction}

It has been suggested that different FGFR subtypes may heterodimerize in vivo (Bellot et al., 1991; Ueno et al., 1992). If heterodimers between XFGFR1 and XFGFR4 were incapable of triggering signaling, each subtype receptor monomer would behave as a dominant-negative inhibitor of other subtypes. If that were true, the heterodimers would suppress signaling even in the presence of excess amounts of ligands. However, whether heterodimers between XFGFR1-ICD and XFGFR4-ICD actually engage in signaling or are inactive complexes has not been determined. To examine this, we used dimerization system in which two different protein molecules are assembled via AP21967 (Fig. 5). XFGFR1-ICD and XFGFR4-ICD were fused to an AP21967binding site, FKBP, to yield iXFGFR1k and XFGFR4k, respectively, or fused to another AP21967-binding site, $\mathrm{FRB}_{2098 \mathrm{~L}}$, to yield iXFGFR1r and XFGFR4r, respectively (Fig. 6A). Since AP21967 forms a bridge between FKBP and $\mathrm{FRB}_{2098 \mathrm{~L}}$, only heterodimers or homodimers of the XFGFR ICDs could be formed in embryos injected with an appropriate combination of mRNAs
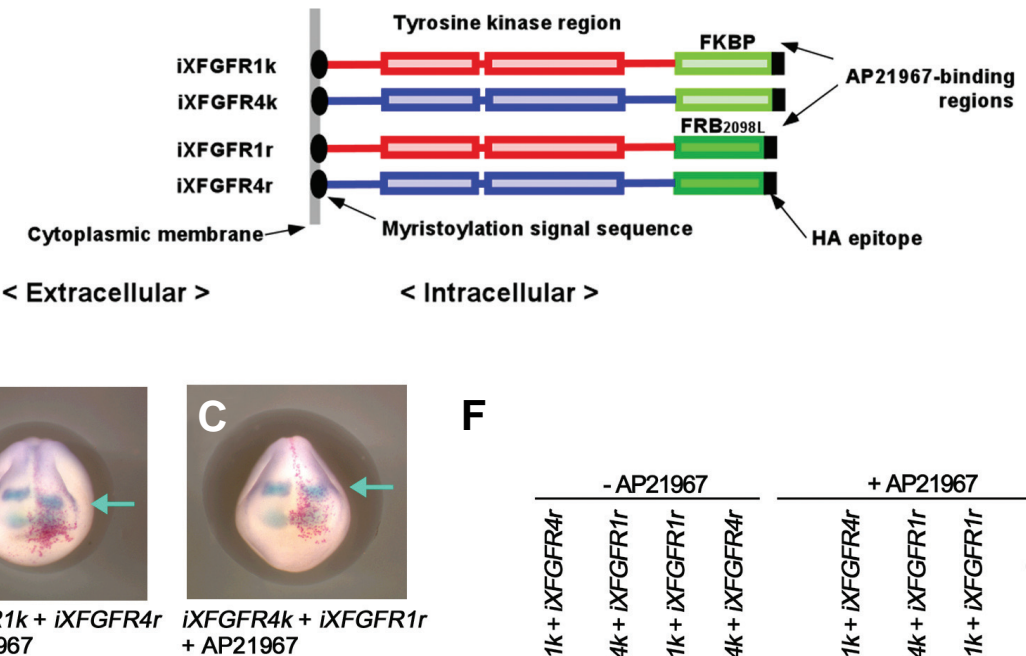

$\mathbf{F}$ + AP21967
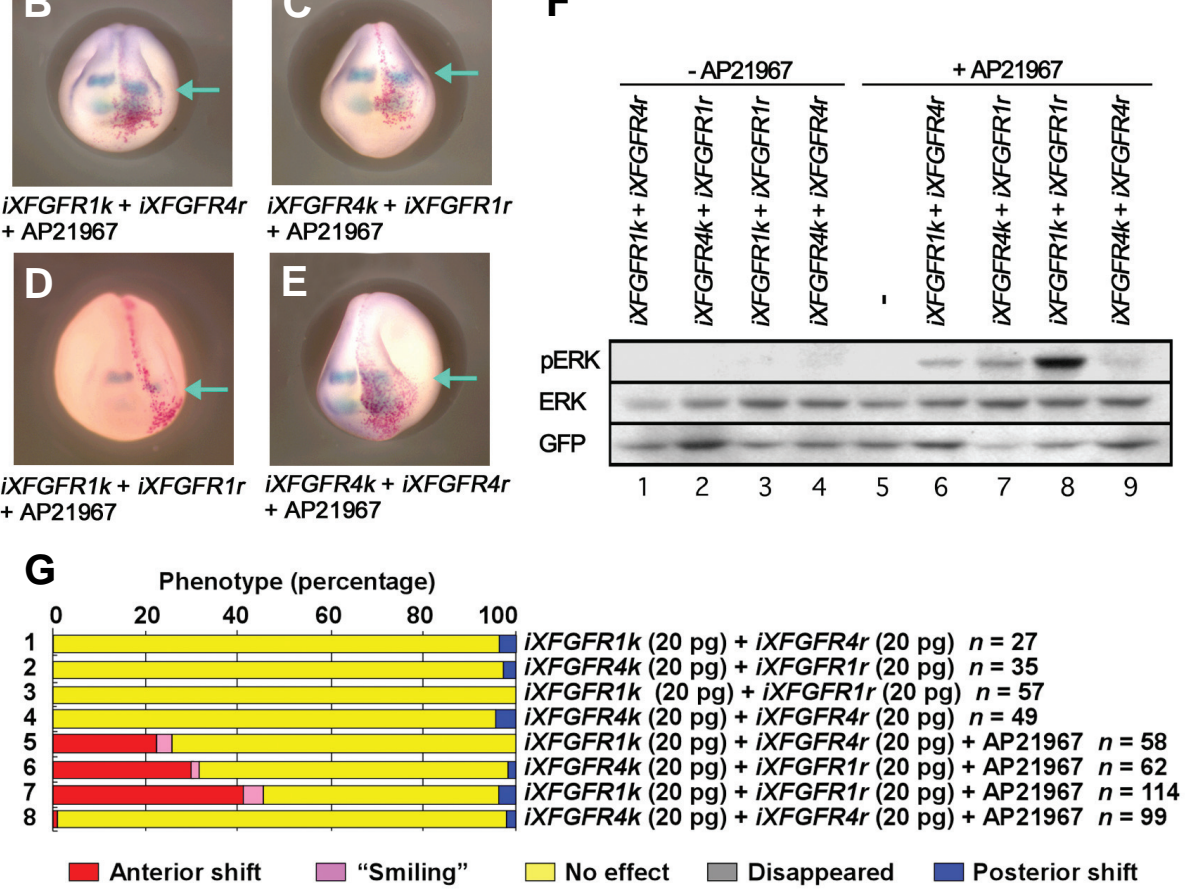

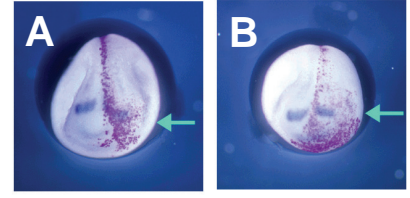

caCDC42 $d n C D C 42$
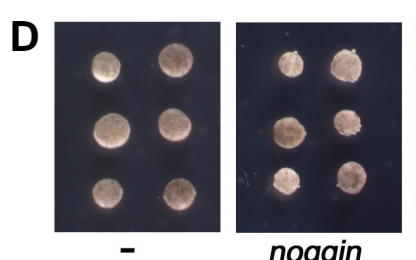
noggin
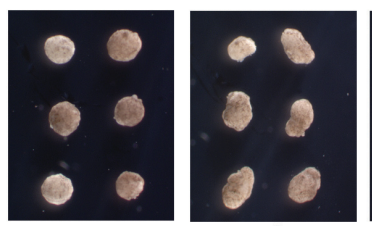

noggin

$+i X F G F R 4$ + iXFGFR1 + iXFGFR4 + AP20187 + AP20187
C

Phenotype (percentage)

$\begin{array}{llllll}0 & 20 & 40 & 60 & 80 & 100\end{array}$

1 in 1 dnCDC42 (RNA, $50 \mathrm{pg}) n=103$

$\square$ Anterior shift $\square$ No effect $\square$ Disappeared $\square$ Posterior shift

implicating fate determination as a regulatory factor. Increasing FGF signaling may confer more posterior fate to cells, shifting the neural marker expression anteriorly, while decreasing signaling would shift expression posteriorly.

In addition to cell fate determination, neural tissue development depends on extensive cell movements. Convergent extension is essential for tissue elongation along the anteroposterior axis, and is prominent only posterior to the MHB in neural ectoderm (Keller et al., 1992), where $X F G F R 1$ expression predominates over XFGFR4 expression (Fig. 1). FGF signaling has been implicated in convergent extension (Nutt et al., 2001; Yokota et al., 2003; Aarmar and Frank, 2004). Thus, when expression of XFGFR1 or XFGFR4 is altered toward increasing the output of FGFR signaling, the area of extensive tissue lengthening may expand into the anterior neural region, leading to an anterior shift in Xpax2 expression. Likewise, reducing the convergent extension by altering expression in the opposite way may shift the marker expression posteriorly.

To determine whether convergent

Fig. 7. Involvement of convergent extension in the positioning of Xpax2 expression and differential activities of the ICDs of XFGFR1 and XFGFR4. (A,B) Xpax2 expression was shifted anteriorly by caCDC42 under the regulation of a CMV promoter (A), whereas dnCDC42 mRNA induced a posterior shift (B). (C) Summary of injections of CDC42 constructs. (D,E) Dimerization of iXFGFRs was induced by AP20187 at stage 11.5 in animal caps that had been injected with noggin mRNA. Cap elongation was assessed based on the ratio of the maximum width to the minimum width of the cap at stage 19 (E). Data are expressed as means +/- s.d.

(Fig. 5).

Both heterodimers (iXFGFR1k-iXFGFR4r and iXFGFR1riXFGFR4k) induced an anterior shift in Xpax2 expression (Fig. 6 B,C,G lines 5 and 6), albeit less efficiently than the iXFGFR1kiXFGFR1r homodimers did (Fig. 6G line 7). Neither anterior shift of Xpax2 expression (Fig. 6 E,G line 8) nor ERK activation in animal caps (Fig. 6F lane 9) was induced by iXFGFR4k-iXFGFR4r homodimers, indicating reduced dimerization capability of this system in comparison with the system that used AP20187. Consequently, the heterodimer activities were moderate in terms of ERK activation and marker shifting compared to the activities of the homodimerized XFGFR1-ICD and XFGFR4-ICD molecules. Although the efficiency of heterodimerization in vivo is unknown, it is very likely that total FGF signaling output would not differ much in the absence and presence of heterodimerization. We concluded that heterodimerization would not inhibit the intrinsic signaling activities of the ICDs of either receptor subtype.

Convergent extension as well as cell fate determination is likely to determine the positioning of marker expression downstream of receptor competition

Finally, we addressed the question of the cellular functions that define the positioning of marker expression as a consequence of receptor competition. It is well established that FGFs posteriorize neural tissues (Cox and Hemmati-Brivanlou, 1995; Kengaku and Okamoto, 1995; Pownall et al., 1996; McGrew, et al., 1997; Holowacz and Sokol, 1999; Hongo etal., 1999; Ribisi etal., 2000), extension plays a role in the positioning of Xpax2expression, we examined the effects of up- and down-regulation of CDC42, whose activity is required for such movements (Djiane et al., 2000; Choi and Han, 2002). caCDC42 was expressed under the control of the CMV promoter following the midblastula transition, since direct injection of $c a C D C 42 \mathrm{mRNA}$ impairs early embryonic cytokinesis (Drechsel et al., 1996; Djiane et al., 2000). Xpax2 expression was shifted anteriorly by the caCDC42plasmid (Fig. $7 \mathrm{~A}, \mathrm{C}$ line 1) with low efficiency, possibly in part due to unequal expression in DNA-injected embryos (for example, see Kroll and Amaya, 1996). dnCDC42 mRNA, on the other hand, induced a posterior shift in Xpax2expression (Fig. 7 B,C line 2). Gain or loss of CDC42 activity has been found to inhibit proper convergent extension in whole embryos as well as in activin-treated animal caps (Djiane et al., 2000; Choi and Han, 2002). In our experiments on anteriorly targeted expression, $c a C D C 42$ and $d n C D C 42 \mathrm{dem}$ onstrated opposing effects, indicating the involvement of convergent extension in marker expression positioning.

The intrinsic elongation activities of XFGFR1-ICD and XFGFR4ICD on neuralized animal caps were compared by adding AP20187 at stage 11.5, when competency for mesoderm formation had been lost (Pownall et al., 2003). Elongation of noggin-expressing caps was induced by injection of $I X F G F R 1 \mathrm{mRNA}$, but little effect was observed with iXFGFR4 mRNA (Fig. 7 D,E). This marked difference between the elongation abilities of iXFGFR1 and iXFGFR4 may account for the opposing effects of XFGFR1 and XFGFR4 on marker expression positioning. 
It seems unlikely that the major outcome of the proposed receptor competition is manifested in the form of apoptosis, since neither the anti-apoptotic protein Bcl2 (Yeo and Gautier, 2003) nor the pro-apoptotic protein Bax affected the positioning of marker expression in mRNA injection experiments (not shown). However, temporally controlled apoptosis may be required for regulation of marker expression positioning.

Since the results of this study suggested that well-tuned convergent extension directed by FGF signaling regulates the normal positioning of marker expression, it is likely that cell movements as well as cell fate determination play roles, with both functioning downstream of the receptor competition.

\section{Discussion}

The confinement of expression of XFGFR4 to the anterior portion of prospective and developing neural region in Xenopus contrasts sharply with the broad distribution of XFGFR1 expression. The current study revealed an exquisitely balanced relationship between the expression profiles of these two receptor genes and normal early neural development, demonstrating coordinated actions of the receptors. We propose that receptor competition for ligands underlies this coordination by regulating the downstream pathways.

\section{XFGFR1 and XFGFR4 compete for ligands to regulate down- stream signaling during early neural development}

The differential expression of XFGFR1 and XFGFR4 are evident by the early gastrula stage. Increasing or decreasing the level of expression of each receptor gene affects the anteroposterior positioning of regional neural marker expression. This observation was made possible by carefully targeted injection of reagents at doses low enough to avoid the gross gastrulation defects caused by impaired mesoderm development. The marker shift assay provided us with a sensitive means of identifying the molecules that affect the expression domains of the regional marker Xpax2. Notably, the assay showed that XFGFR1 and XFGFR4 have opposing effects, an anterior shifting effect by XFGFR1 and a posterior shifting effect by XFGFR4. We also found that the ECDs were interchangeable between XFGFR1 and XFGFR4 without changing the specificity in direction of shifting. Therefore, despite the existence of several FGF ligands in the developing anterior neural region, each with different affinities for the respective XFGFRs, the overall extracellular signal levels received by XFGFR1-ECD and XFGFR4-ECD were comparable, highlighting the large difference in the properties of the ICDs.

The opposing effects of XFGFR1 and XFGFR4 seen in the marker shift assays were lost when FGF signaling was activated ligand-independently. Both XFGFR1-ICD and XFGFR4-ICD induced anterior shifting, eliminating intracellular events downstream of the receptors as determinants of the opposing effects. Together with a marked quantitative difference between the potencies of FGFR1-ICD and FGFR4-ICD for activating downstream pathways, this observation strongly supports the hypothesis that competition for ligands occurs during receptor activation at the cell surface. No receptor activation factors other than those related to ligand availability are limited, as evidenced by the result with FGF overexpression; the size reduction of anterior neural structures both on injected and non-injected sides of the embryos, which reflects the diffusive nature of FGFs (Christen and Slack, 1999; Fletcher et al., 2006). This phenotype was rescued by coexpression of XFGFR4. We conclude that ligand availability is limited in the developing anterior region.

Anterior ectodermal cells are rich in XFGFR4 mRNA and thereby should be less potent in signaling under ligand-limiting conditions than the posterior cells. Indeed, the region of low-level ERK activation (Schohl and Fagotto, 2002) coincided with the region of intense XFGFR4expression. We speculate that autocrine FGFs and concomitant XFGFR4 expression are responsible for the weak signaling in this region.

Since the direction of the shift in marker expression caused by altering the Ras and PLC $\gamma$ activation levels was consistent with the postulated receptor competition mechanism, both of these downstream pathways are likely to be involved in the XFGFRrelated positioning of marker expression. However, XFGFR1 ${ }_{\text {Y762F, }}$ which has an amino acid substitution in the region required for interaction with PLC $\gamma$, maintained substantial anterior shifting activity for marker expression. Whether the Ras and PLC $\gamma$ pathways function independently is unclear, because Ras-PLC $\gamma$ crosstalk may occur (Pawson and Saxton, 1999). It is possible that failure to directly activate this pathway by XFGFR may be partly compensated by Ras signaling.

The differential abilities of XFGFR1 and XFGFR4 to activate ERK (through the Ras pathway) and to induce $X b r a$ expression (through the Ras and PI3K pathways) were confirmed for ca and iXFGFRs, and the relative effects of the PLC $\gamma$-binding mutations on marker shifting were virtually equivalent in XFGFR1 and XFGFR4. Though it is unlikely that the extent of the relative contribution of each downstream pathway to the positioning of marker expression is identical in XFGFR1 and XFGFR4 signaling, our results suggest that the qualitative properties of signaling elicited by the two XFGFRs are highly similar and that the quantitative difference in combined signaling levels of the intracellular pathways downstream of the two receptors is important for the positioning of marker expression. Umbhauer et al. (2000) used chimera receptors in which the XFGFR ICD is fused to the ECD of platelet-derived growth factor receptor or a mutant form of torso and found that XFGFR4 is incapable of activating RAS/ERK. However, FGFR4 has been shown to weakly but significantly activate ERK in other experimental systems (Vainikka etal., 1994; Shauol et al., 1995; Raffioni et al., 1999). This discrepancy may reflect different efficiencies of receptor activation. It should be noted, however, that our results do not exclude possible qualitative differences between XFGFR1 and XFGFR4 in signaling properties crucial for other developmental processes. Nor do our results rule out intracellular competition between XFGFR1 and XFGFR4 signaling either where both signaling pathways are highly activated by abundant ligands or in certain cells that produce only limited amounts of common signaling components.

\section{Cell fate determination and convergent extension as plau- sible cellular activities that determine the positioning of marker expression}

The anterior shifting and posterior shifting of marker expression can be explained by posteriorization and anteriorization, respectively, of cell fate, which is determined by FGF signaling levels. In addition to being affected by cell fate determination, early neural development is substantially affected by cell move- 
ments, and marker expression patterns may also be regulated by morphogenetic processes. In fact, our marker shift assay of mutant forms of CDC42 demonstrated that convergent extension is involved in the positioning. Moreover, XFGFR1-ICD was more efficient than XFGFR4-ICD in elongating neuralized animal caps. These findings suggest that both cell fate determination and convergent extension determine the positioning of marker expression by the receptor competition mechanism. It is noteworthy that the pronounced extension of the developing Xenopus neural tissue is restricted posterior to the prospective midbrain and relatively little extension takes place in more-anterior regions (Keller et al., 1992), where XFGFR4 expression is abundant.

When the expression levels of XFGFRs were altered, the location of $R \times 1$ expression was less affected compared to that of Xpax2, En2and Krox20and no significant shift of Bf1 expression was observed (not shown). The marker shifting may occur only within the defined area of neural region, suggesting a more important role of cell movements for the phenotype. We were unable to test posterior makers, such as HoxB9, in marker shift assay since the injected site was not appropriate to examine their expression (shifting injection site towards the posterior led to gastrulation defects).

\section{Competition between XFGFR1 and XFGFR4 as an efficient mechanism to maintain low FGF signaling}

Ligand reception under locally restricted ligand-limiting conditions has been demonstrated in regard to several receptors (Hajnal et al., 1997; Gurdon and Bourillot 2001; and the references therein), with signaling events mediated by only one type of receptor. If related receptors sharing affinities for a common ligand(s) are coexpressed, a ligand-limiting state inevitably produces local receptor competition like the competition described here.

A hallmark of the competition between XFGFR1 and XFGFR4 described here is that the competing receptors elicit qualitatively similar but quantitatively different intracellular signaling. Furthermore, heterodimers between XFGFR1 and XFGFR4 are not defective forms but engage in signal transduction. Since the activation levels of heterodimers were intermediate between those of the homodimers in both the marker shift assay and the ERK assay, the intrinsic activities of the receptor ICDs are manifested irrespective of the heteroodimers/homodimers ratio. Once a ligand-limiting state disappears, the responding cell may virtually display the maximal signaling abilities of the ICDs. Therefore, the setting for competition between XFGFR1 and XFGFR4 is distinct from that for regulation of signaling-competent receptors by receptors lacking domains required for activation of the downstream pathways; the suppressive effects of these defective receptors on signaling events are invariant. For example, BAMBI, that is related to BMPR but kinase inactive, binds to type I BMP receptor (Onichtchouk et al., 1999) and thus would suppress BMP signaling even in the presence of saturating levels of ligands. Planarian Nou-darake (Cebria et al., 2002) and its Xenopushomologue XFGFRL1 (Hayashi et al., 2004) are FGFRrelated proteins lacking an intracellular kinase domain and thus should act like dnFGFR (Amaya et al., 1991). Another example of a receptor lacking a kinase domain in its ICD is IGF2R. IGF2R reduces the level of circulating IGF2 by its ligand clearance activity, which decreases the activity of other IGF receptors (Lau et al., 1994; Wang, Z.-Q. et al., 1994; Ludwig et al., 1996). By contrast, local competition for ligands between receptors with low or high signal transduction potency (like the competition between XFGFR1 and XFGFR4) is an efficient mechanism for maintaining low signaling levels, and yet cells are able to prime an immediate response to increased local ligand availability.

Since weak FGF signaling has been implicated in Xenopus neural induction (Hongo et al., 1999; Delaune et al., 2005), it is highly likely that receptor competition in the prospective anterior region is also required for neural induction. The inhibitory effect of dnXFGFR4 in neural development (Hongo etal., 1999; Hardcastle et al., 2000; Kuroda et al., 2004; Delaune et al., 2005) may be explained by imbalanced receptor competition. At later stages of development, regional differentiation of neural tissue seems to proceed in response to increasing FGF levels from several local sources. Receptor competition may also be important for ERK activation triggered by wounding in the early embryos. Although conflicting observations have been made in regard to the FGFRdependency of this transient ERK activation (LaBonne and Whitman, 1997; Christen and Slack, 1999), competing receptors can efficiently respond to FGFs (such as bFGF, which lacks the secreting signal sequence) released from injured cells.

Another feature of competition between receptors having different potencies is that the receptor with lower potency for activating downstream pathways moderates cell responsiveness to increasing concentrations of local ligand. Cells respond irreversibly to the highest concentration of ligand during the period of competency (Gurdon et al., 1995; Dyson and Gurdon, 1998). Competition should ensure the correct choice of cell fate and behavior to counter fluctuating ligand concentrations.

A simple inference from the competition between XFGFR1 and XFGFR4 during early neural development is that competition for ligands may occur among all subtype FGFRs. FGFRs are often coexpressed in vertebrate tissues, and although it is evident that receptor-ligand specificity is primarily important in FGF signal transduction (Yu et al., 2000), there are overlapping specificities in ligand affinities for the different subtype FGFRs (Eswarakumar and Schlessinger, 2005). Receptor competition for ligands may therefore be involved in many other FGF signaling events where ligand availability is limiting.

Intuition suggests that local receptor competition in signaling may be integrated in various cellular systems, although no clear examples have been reported, perhaps because of the general difficulty in determining the nature of local ligand-receptor relationships where multiple ligands and receptors co-exist. The coordinated actions of XFGFR1 and XFGFR4 in the developing anterior region of Xenopus provide a simple ligand-receptor relationship in that the ligand-binding domains of the receptors are interchangeable with respect to effect on marker expression patterns. Another difficulty in identifying receptor competition is that competitive states in vivo cannot be easily reproduced in conventional cell culture systems; while ligand is available in restricted extracellular space in vivo, exogenous ligand is added to a large volume of medium in cell culture. Reducing the concentration of the ligand added in cell culture merely results in lower occupancy of each receptor by the ligand without any mutual influence among receptors during the limited time required for the interpretation of signal strength.

In conclusion, the results of the present study shed light on a 
potentially important aspect of signal regulation in cells, that is, local competition for ligands between/among receptors with quantitatively different abilities to activate their common downstream pathways. This regulatory mechanism may be integrated in the process of interpreting extracellular signals in many biological events.

\section{Materials and Methods}

\section{Constructs and synthetic capped RNAs}

All of the XFGFRs (Hongo et al., 1999) and their derivatives that were used in this study, except for those used in the inducible dimerization systems, were cloned in pST64T. Chimeras between XFGFR1 and $X F G F R 4$ were generated by interchanging $N$ hel-Ncol fragments containing the ECD regions. Constitutively active (ca)XFGFR1 and caXFGFR4 carry a C337Y amino acid substitution and a C345Y amino acid substitution, respectively. The nucleotide sequences of resXFGFR1 and resXFGFR4 around the initiation codons are: ATCGCGGCCGCCACCATGTTTAGT (resXFGFR $)$ and

ATCGCGGCCGCCACCATGAGCGGCAGCGTGAGGAGGTCT (resXFGFR4), respectively. To construct iXFGFR1 and IXFGFR4, the myristoylation signal sequence and $2 \mathrm{x} \mathrm{FKB}_{\mathrm{P} 36 \mathrm{~V}}-\mathrm{HA}$ (ARIAD; www.ariad.com/regulationkits) were fused via a Sal site, and the fusion was cloned into a pCS2+ derivative with a disrupted Sal site upstream of the CMV promoter. The XFGFRs ICDs were amplified by PCR for XFGFR1-ICD:

forward primer ATACTCGAGATGAAGCACCCGTCGAAGAAG and reverse primer TTAACTGGAGGCGTTTTTTTAGTCCACCATTGG; for XFGFR4-ICD:

forward primer TATACTCGAGATGCAGACACCGCACAGCAAG and reverse primer TTAACTCGAGAGTCCCAAGGTGAGTGTGAAC), and then were cut with $X$ hol and cloned into the Sal site in the above plasmid. The same strategy was used for the heterodimer constructs except for the use of 1x FKBP-HA (for iXFGFR1k and iXFGFR4K) or 1x FGB-HA (for iXFGFR1r and iXFGFR4h) (ARIAD; www.ariad.com/ regulationkits) instead of $2 x \mathrm{FKBP}_{36 \mathrm{~V}}-\mathrm{HA}$. XPLC $\gamma 1 a$ (deposited in GenBank, AB287408) was isolated from a lamda cDNA library based on the partial sequence of this gene (GenBank AF090111) and cloned in pCS2+. XNras (Spevak et al., 1993) was obtained by RT-PCR and cloned in PSP64T after introducing a G12V amino acid substitution to generate caXNras. caCDC42 (CDC42 $\left.{ }_{G 12 V}\right)$ and $d n C D C 42\left(C D C 42_{T 17 N}\right)$ were obtained from the UMR cDNA Resource Center (Rolla, USA) and cloned in pCS2+ and pSP64T, respectively. dnRas, XeFGF, XFGF8, dnBMPR, noggin, $n L a c Z$, and $G F P$ were cloned in pSP64T. Amino acid substitutions to generate caXFGFR1, caXFGFR4, XFGFR $1_{\text {Y762F }}$, XFGFR $_{{ }_{Y 766 F}}$, and caXNras were carried out with Mutan-Express (Takara). Capped RNAs transcribed on pSP64T derivatives were purified with Dynabeads oligo dT (Dynal).

\section{Morpholino nucleotides}

The MO sequences (Gene Tools) used were: XFGFR1-MO, CCGGAGAACATCCCAAGTTGGCTAG; XFGFR4-MO, an equimolar mixture of GCTTCTTCTTACAGATCCAGACATG (for XFGFR4a) and GCTTCTTCTTATGGATCCAGACATG (for XFGFR4b); and XPLC 1 1-MO, CTGCTCCTGCTGTAAATCCACCAAG. Standard Control (Gene Tools) was used as the control MO.

\section{$R T-P C R$}

RT-PCR was carried out with ExTaq polymerase (Takara) as described previously (Hongo et al., 1999; Bottcher et al., 2004). The nucleotide sequence of the primers (and number of PCR cycles) were as follows:

for XFGFR1 (28 cycles),

forward AAGTGGAGCCATATTCAGCTCG and reverse GGAGTTCTCCGAAGCTTTCTCC; for XFGFR4 (28 cycles), ATGAAGCCAACTGGAAGGAACC and reverse AGATGCCAACGAGTCAACAACG;

for histone 4 (26 cycles),

forward CGGGATAACATTCAGGGTA and

reverse TCCATGGCGGTAACTGTC;

for Xbra (28 cycles),

forward GCTGGAAGTATGTGAATGGAG and reverse TTAAGTGCTGTAATCTCTTCA;

for $G F P(24$ cycles), forward CCATCTTCTTCAAGGACGACGG and reverse ATCTTGAAGTTCACCTTGATGC.

\section{Immunoblot analysis}

Immunoblotting was carried out as described previously (Bottcher et al., 2004). Anti-diphosphorylated-extracellular signal-regulated kinase (ERK), clone MAPK-YT (Sigma), anti-ERK1, sc-94 (Santa Cruz), and anti-GFP, A6655 (Invitrogen) were used as primary antibodies.

\section{Embryo manipulations}

Embryos were obtained by natural mating. Microinjection was carried out at the 2-cell stage for animal cap assay and at the 8-cell stage for marker shift assay. The amounts of mRNAs injected other than those indicated in Figures were: nlacZ, 100-250 pg; GFP, 40 pg; noggin, 50 pg. Animal caps were excised at stage 9 and cultured in $0.5 \times$ MBS (Hongo et al., 1999). The concentrations of AP20187 and AP21967 (ARIAD) used to dimerize the inducible receptors were $1.25 \mu \mathrm{M}$ (Pownall et al., 2003) and $4.5 \mu \mathrm{M}$, respectively. Whole-mount in situ hybridization was carried out as described previously (Hongo et al., 1999) after staining for $n L a c Z$ expression with Red-Gal (Research Organics).

\section{Note}

The secreted ECDs of XFGFs were highly diffusive and distributed across the midline of the embryo when their mRNAs were unilaterally injected. dnXFGFR1 and dnXFGFR4 caused a posterior shift, which could be explained by non-subtype specific association between the dnFGFRs and endogenous FGFRs (Bellot etal., 1991; Ueno et al., 1992). Therefore, all these constructs were not used in this study.

\section{Acknowledgment}

Materials were kindly provided by A. Brandly, R. Davis, R. Harland, I. Hongo, H. Isaacs, J. Slack, and M. Taira. We thank ARIAD Pharmaceuticals for the dimerization systems. M.Y. is grateful to I. Hongo for advice and to the members of Molecular Neurobiology Group AIST for support.

\section{References}

AAMAR, E. and FRANK, D. (2004). Xenopus Meis3 protein forms a hindbrain inducing center by activating FGF/MAP kinase and PCP pathways. Development 131: 153-163.

AMAYA, E., MUSCI, T. J. and KIRSCHNER, W. (1991). Expression of a dominant negative mutant of the FGF receptor disrupts mesoderm formation in Xenopus embryos. Cell, 66: 257-270.

BELLOT, F., CRUMLEY, G., KAPLOW, J. M., SCHLESSINGER, J., JAYE, M. and DIONNE, C. A. (1991). Ligand-induced transphosphorylation between different FGF receptors. EMBO J. 10: 2849-2858.

BOTTCHER, R., POLLET, N., DELIUS, H. and NIEHRS, S. (2004). The transmembrane protein XFLRT3 forms a complex with FGF receptors and promotes FGF signalling. Nature Cel/ Biol. 6: 38-44.

CARBALLADA, R., YASUO, H. and LEMAIRE, P. (2001). Phosphatidylinositol-3 kinase acts in parallel to the ERK MAP kinase in the FGF pathway during Xenopus mesoderm induction. Development, 128: 35-44.

CEBRIA, F., KOBAYASHI, C., UMESONO, Y., NAKAZAWA, M., MINETA, K. IKEO, K., GOJOBORI, T., ITO, M., TAIRA, M., ALVARADO, A. and AGATA, K. (2002). FGFR-related gene nou-darake restricts brain tissues to the head region 
of planarians. Nature 419: 620-624.

CHOI, S.-C. and HAN, J.-K. (2002) XenopusCdc42 regulates convergent extension movements during gastrulation through $\mathrm{Wnt} / \mathrm{Ca}^{2+}$ signaling pathway. Dev. Biol. 244: 342-357.

CHRISTEN, B. and SLACK, J. M. W. (1997). FGF-8 is associated with anteroposterior patterning and limb regeneration in Xenopus. Dev. Biol. 192: 455-466.

CHRISTEN, B. and SLACK, J. M. W. (1999). Spatial response to fibroblast growth factor signalling in Xenopus embryos. Development 126: 119-125.

COX, W. G. and HEMMATI-BRIVANLOU, A. (1995). Caudalization of neural fate by tissue recombination and bFGF. Development 121: 4349-4358.

DAILEY, L., AMBROSETTI, D., MANSUKHANI, A. and BASILICO, C. (2005). Mechanisms underlying differential responses to FGF signaling. Cytokine \& Growth Factor Reviews 16: 233-247.

DELAUNE, E., LEMAIRE, P. and KODJABACHIAN, L. (2005). Neural induction in Xenopus requires early FGF signalling in addition to BMP inhibition. Development 132: 299-310.

DENG, T. and KARIN, M. (1994). c-Fos transcriptional activity stimulated by H-Rasactivated protein kinase distinct from JNK and ERK. Nature 371: 171-175.

DJIANE, A., RIOU, J.-F., UMBHAUER, M., BOUCAUT, J.-C. and SHI, D.-L. (2000). Role of frizzled 7 in the regulation of convergent extension movements during gastrulation in Xenopus laevis. Development 127: 3091-3100.

DRECHSEL, D. N., HYMAN, A. A., HALL, A. and GLOTZER, M. (1996). A requirement for Rho and Cdc42 during cytokinesis in Xenopus embryos. Curr. Biol. 7: 12-23.

DYSON, S. AND GURDON, J. B. (1998). The interpretation of position in a morphogen gradient as revealed by occupancy of activin receptors. Cel/93: 557-568.

ESWARAKUMAR, V. P. and SCHLESSINGER, I. L. J. (2005). Cellular signaling by fibroblast growth factor receptors. Cytokine \& Growth Factor Reviews 16: 139149.

FLETCHER, R. B., BAKER, J. C. and HARLAND, R. M. (2006). FGF8spliceforms mediate early mesoderm and posterior neural tissue formation in Xenopus. Development 133: 1703-1714.

GOLUB, R., ADELMAN, Z., CLEMENTI, J., WEISS, R., BONASERA, J. and SERVENTNICK, M. (2000). Evolutionarily conserved and divergent expression of members of the FGF receptor family among vertebrate embryos, as revealed by FGFR expression patterns in Xenopus. Dev. Genes Evol. 210: 345-357.

GURDON, J. B. and BOURILLOT, P.-Y. (2001). Morphogen gradient interpretation. Nature 413, 797-803.

GURDON, J. B., MITCHELL, A. and MAHONY, D. (1995). Direct and continuous assessment by cells of their position in a morphogen gradient. Nature 376: 520521.

HAJNAL, A., WHITFIELD, C. W. and KIM, S. K. (1997) Inhibition of Caenorhabditis elegance vulval induction by gap-1 and by let-23 receptor tyrosince kinase. Genes Dev. 11: 2715-2728.

HARDCASTLE, Z., CHALMERS, A. D. and PAPALOPULU, N. (2000). FGF-8 stimulates neuronal differentiation through FGFR-4a and interferes with mesoderm induction in Xenopus embryos. Curr. Biol. 10: 1511-1514.

HAYASHI, S., ITOH, H., TAIRA, S., AGATA, K. and TAIRA, M. (2004). Expression patterns of XenopusFGF-receptor-like 1/nou-darake in early Xenopus development resemble those of planalian nou-darake and Xenopus FGF8. Dev. Dynamics 230: 700-707.

HELLER, N. and BRANDLI, A. W. (1997). Xenopus Pax-2displays multiple splice forms during embryogenesis and pronephric kidney development. Mech. Dev. 69: 83-104.

HOLOWACZ, T. and SOKOL, S. (1999). FGF is required for posterior neural patterning but not for neural induction. Dev. Biol. 205: 296-308.

HONGO, I., KENGAKU, M. and OKAMOTO, H. (1999). FGF signalling and the anterior neural induction in Xenopus. Dev. Biol. 216: 561-581.

HUGHES, S. E. (1997). Differential expression of the fibroblast growth factor receptor (FGFR) multigene family in normal human adult tissues. J. Histochem. Cytochem. 45: 1005-1019.

ISAACS, H. V., TANNAHILL, D., and SLACK, J. M. W. (1992). Expression0of a novel FGF in Xenopus embryo: A new candidate inducing factor for mesoderm formation and anteroposterior specification. Development 114: 711-720.
KELLER, R., SHIH, J. and SATER, A. (1992). The cellular basis of the convergence and extension of the Xenopus neural plate. Dev. Dynamics 193: 199-217.

KENGAKU, M. and OKAMOTO, H. (1995). bFGF as a possible morphogen for the anteroposterior axis of the central nervous system in Xenopus. Development 121: $3121-3130$.

KROLL, K. L. and AMAYA, E. (1996). Transgenic Xenopus embryos from sperm nuclear transplantations reveal FGF signaling requirements during gastrulation. Development 122: 3173-3183.

KURODA, H., WESSELY, O. and DE ROBERTIS, E. M. (2004). Neural induction in Xenopus: requirement for ectodermal and endomesodermal sigals via Chordin, Noggin, $\beta$-catenin, and Cerberus. PLOS Biol. 2: 623-634.

LABONNE, C. and WHITMAN, M. (1997). Localization of MAP kinase activity in early Xenopusembryos: implications for endogenous FGF signaling. Dev. Biol. 183: 9-20.

LAU, M. M. H., STEWART, C. E. H., LIU, Z., BHATT, H., ROTWEIN, W. and STEWART, C. L. (1994). Loss of the imprinted IGF2/cation-independent mannose 6-phosphate receptor results in fetal overgrowth and perinatal lethality. Genes Dev. 8: 2953-2963.

LUDWIG, T., EGGENSCHWILER, J., FISHER, P., D’ERCOLE, A. J., DAVENPORT, M. L. and EFSTRATIADIS, A. (1996) Mouse mutants lacking the type 2 IGF receptor (IGF2R) are rescued from perinatal lethality in Igf2 and Igf1rnull backgrounds. Dev. Biol. 177: 517-535.

LUNN, J. S., FISHWICK, K. J., HALLEY, P. A. and STOREY, K. G. (2007). A spartial and temporal map of FGF/Erk1/2 activity and response repertories in the early chick embryo. Dev. Biol., 301: 536-552.

McGREW, L. L., HOPPLER, S. and MOON, R. T. (1997). Wnt and FGF pathways cooperatively pattern anteroposterior neural ectoderm in Xenopus. Mech. Dev. 69: 105-114

MOHAMMADI, M., DIONNE, C. A., LI, W., LI, N., SPIVAK, T., HONEGER, A. M., JAYE, M. and SCHLESSINGER, J. (1992). Point mutation in FGF receptor eliminates phoshatidylinositol hydrolysis without affecting mitogenesis. Nature 358: $681-684$

NEILSON, K. M. and FRIESEL, R. E. (1995). Constitutive activation of fibroblast growth factor receptor- 2 by a point mutation associated with Crouzon syndrome. J. Biol. Chem. 270: 26037-26040.

NUTT, S., L., DINGWELL, K., S., HOLT, C. E. and AMAYA, E. (2001). Xenopus Sprouty2 inhibits FGF-mediated gastrulation movements but does not affect mesoderm induction and patterning. Genes \& Dev., 15: 1152-1166.

ONICHTCHOUK, D., CHEN, Y-G, DOSCH, R., GAWANTKA, V., DELIUS, H., MASSAGUE, J. AND NIEHRS, C. (1999). Silencing of TGF- $\beta$ signaling by the pseudoreceptor BAMBI. Nature 401: 480-484.

ORNITZ, D. M., XU, J., COLVIN, J. S., McEWEN, D. G., MACARTHUR, C. A., COULIER, F., GAO, G. and GOLDFARB, M. (1996). Receptor specificity of the fibroblast growth factor family. J. Biol. Chem. 271: 15292-15297.

PAWSON, T. and SAXTON, T. M. (1999). Signaling networks-do all roads lead to the same genes? Cell 97: 675-678.

POWNALL, M. E., TUCKER, A. S., SLACK, J. M. and ISAACS, H. V. (1996). eFGF, $X$ cad3and Hoxgenes form a molecular pathway that establishes the anteroposterior axis in Xenopus. Development 122: 3881-3892.

POWNALL, M. E., WELM, B. E., FREEMAN, K. W., SPENCER, D. M., ROSEN, J. M. and ISAACS, H. V. (2003). An inducible system for the study of FGF signaling in early amphibian development. Dev. Biol. 256: 89-99.

RAFFIONI, S., THOMAS, D., FOEHR, E., THOMPSON, L. M. and BRADSHAW, R (1999). Comparison of the intracellular signaling responses by three chimeric fibroblast growth factor receptors in PC12 cells. Proc. Natl. Acad. Sci. USA 96: 7178-7183

RIBISI, S., JR, MARIANI, F. V., AAMAR, E., LAMB, T. M., FRANK, D. and HARLAND, R. M. (2000). Ras-mediated FGF signaling is required for the formation of posterior but not anterior neural tissue in Xenopus laevis. Dev. Biol. 227: 183-196.

RIOU, J.-F., CLAVILIER, L. and BOUCAUT, J.-C. (1996). Early regionalized expression of a novel Xenopusfibroblast growth factor receptor in neuroepithelium. Biochem. Biophys. Res. Commun. 218: 198-204.

SHAOUL, E., REICH-SLOTKY, R., BERMAN, B. and RON, D. (1995). Fibroblast growth factor receptors display both common and distinct signaling pathways. Oncogene 10: 1553-1561. 
SCHOHL, A. and FAGOTTO, F. (2002). $\beta$-catenin, MAPK and Smad signaling during early Xenopus development. Development 129: 37-52.

SHINGA, J., ITOH, M., SHIOKAWA, K., TAIRA, S. and TAIRA M. (2001). Early patterning of the prospective midbrain-hindbrain boundary by the HES-related gene XHR1 in Xenopus embryos. Mech. Dev. 109: 225-239.

SPEVAK, W., KEIPER, B. D., STRATOWA, C. and CASTANO'N, M. J. (1993). Saccharomyces cerevisiae cdc15 mutants arrested at a late stage in anaphase are rescued by Xenopus cDNAs encoding $\mathrm{N}$-ras or protein with $\beta$-transducin repeats. Mol. Cell. Biol. 13: 4953-4966.

THISSE, B., THISSE, C. and WESTON, J.A. (1995). Novel FGF receptor (ZFGFR4) is dynamically expressed in mesoderm and neurectoderm during early zebrafish embryogenesis. Dev. Dyn. 203: 377-391.

THOMPSON, J. and SLACK, J. M. W. (1992). Over-expression of fibroblast growth factors in Xenopus embryos. Mech. Dev. 38: 175-182.

UENO, H., GUNN, M., DELL, K., TSENG, A., JR. and WILLIAMS, L. (1992). A truncated form of fibroblast growth factor receptor 1 inhibits signal transduction by multiple types of fibroblast growth factor receptor. J. Biol. Chem. 267: 14701476.

UMBHAUER, M., PENZO-MÉNDEZ, A., CLAVILIER, L., BOUCAUT, J.-C. and RIOU, J. F. (2000). Signaling specificities of fibroblast growth factor receptors in early Xenopus embryo. J. Cell Sci. 113: 2865-2875.

VAINIKKA, S., JOUKOV, V., WENNSTROM, S., BERGMAN, M., PELICCI, P. G. and ALITALO, K. (1994). Signal transduction by fibroblast growth factor receptor-4 (FGFR-4). J. Biol. Chem. 269: 18320-18326.
WANG, J.-K., GAO, G. and GOLDFARB, M. (1994). Fibroblast growth factor receptors have different signaling and mitogenic potentials. Mol. Cell. Biol. 14 181-188.

WANG, Z.-Q., FUNG, M. R., BARLOW, D. P. and WAGNER, E. F. (1994). Regulation of embryonic growth and lysosomal targeting by the imprinted Igf2/ Mpr gene. Nature, 372: 464-467.

WELM, B. E., FREEMAN, K. W., CHEN, M., CONTRERAS, A., SPENCER, D. M and ROSEN, J. M. (2002). Inducible dimerization of FGFR1: development of a mouse model to analyze progressive transformation of the mammary gland. $J$. Cell Biol. 157: 703-714

YAYLAOGLU, M. B., TITMUS, A., VISEL, A., ALVARZ-BOLADO, G., THALLER, C. and EICHELE, G. (2005). Comprehensive expression atlas of fibroblast growth factors and their receptors generated by a novel robotic in situ hybridization platform. Dev. Dynamics 234: 371-386.

YEO, W. and GAUTIER, J. (2003). A role for programmed cell death during early neurogenesis in Xenopus. Dev. Biol. 260: 31-45.

YOKOTA, C., KOFRON, M., ZUCK, M., HOUSTON, D. W., ISAACS, H., ASASHIMA M., WYLIE, C. C. and HEASMAN, J. (2003). A novel role for a nodal-related protein; Xnr3 regulates convergent extension movements via the FGF receptor. Development 130: 2199-2212.

YU, K., HERR, A. B., WAKSMAN, G. and ORNITZ, D. M. (2000). Loss of fibroblast growth factor receptor 2 ligand-binding specificity in Apert syndrome. Proc. Natl. Acad. Sci. USA 97: 14536-14541.

\section{Further Related Reading, published previously in the Int. J. Dev. Biol.}

See our recent Special Issue Epigenetics \& Development edited by Saadi Khochbin and Stefan Nonchev at: http://www.ijdb.ehu.es/web/contents.php?vol=53\&issue=2-3

Expression of Shisa2, a modulator of both Wnt and Fgf signaling, in the chick embryo Thomas A. Hedge and Ivor Mason Int. J. Dev. Biol. (2008) 52: 81-85

Expression and functions of FGF ligands during early otic development Thomas Schimmang

Int. J. Dev. Biol. (2007) 51: 473-481

Fibroblast growth factor receptor 4 (FGFR4) expression in newborn murine calvaria and primary osteoblast cultures.

Simon Cool, Rebecca Jackson, Paul Pincus, lan Dickinson and Victor Nurcombe Int. J. Dev. Biol. (2002) 46: 519-523

FGF signalling and blastema growth during amphibian tail regeneration P Ferretti, F Zhang, L Santos-Ruiz, JDW Clarke Int. J. Dev. Biol. (2001) 45: S127-S128

Targeted over-expression of FGF in chick embryos induces formation of ectopic neural cells.

L Rodríguez-Gallardo, V Climent, V Garciá-Martínez, G C Schoenwolf and I S Alvarez Int. J. Dev. Biol. (1997) 41: 715-723
5 yr ISI Impact Factor $(2008)=3.271$

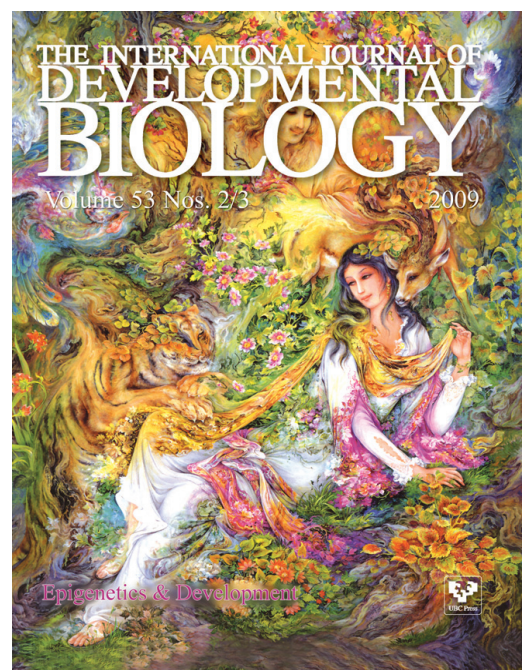

